\title{
The effects of potential self-inflicted harm on obedience to an authority figure
}

\author{
JANIS SACKHOFF and LAWRENCE WEINSTEIN \\ Marymount College, Salina, Kansas
}

\begin{abstract}
In this study we examined the willingness of 17 college students to obey the request of an authority figure despite posted signs that suggested there would be potential harm to the subjects themselves if they complied with the request. More subjects disobeyed the authority figure (obeyed the signs) than obeyed the authority figure. These findings are in contrast to Milgram's (1963) research and suggest that willingness to obey an authority figure is affected by potential harm directed at the subjects themselves.
\end{abstract}

Milgram's (1963) research examined obedience to authority figures. Milgram's study concentrated on subjects' willingness to harm a third person at the request of an authority; no research to date has examined subjects' willingness to comply with a request that would put the subjects themselves in danger. In the present study we investigated the willingness of subjects to carry out an authority's request despite the existence of potential harm to the subjects.

Milgram's (1963) results suggested that subjects seem compelled to obey an authority's request rather than their own internal natures. We hypothesized that subjects in the present study would likewise obey the authority's request without consideration for their own welfare.

\section{METHOD}

\section{Subjects}

The 17 volunteer subjects, 13 females and 4 males, were undergraduate students in various academic classes at a small midwestern college. The treatment of each participant was in accordance with the ethical standards of the American Psychological Association.

An undersheriff from a midwestern county, dressed in full uniform, served as the authority figure in the study (see Figure 1).

\begin{abstract}
Apparatus
To enhance the subjects' belief in the potential danger to themselves, they were taken, one at a time, to a chemistry classroom where they were to take a mock personality inventory. In the classroom was a large cabinet on which were posted three signs: "DANGER," "KEEP OUT," and "Attention: Cabinet contains Hazardous Chemicals intended ONLY for Animal Research. Possible Harm to Humans if exposed!!! DO NOT OPEN" (see Figure 2). A sealed brown box was placed inside the cabinet. A camera hidden behind the subject's chair allowed the experimenters to observe whether the cabinet was opened by the subject. This also allowed the whole experiment to be preserved on videotape. The subjects were timed by a stopwatch to ensure all subjects an equal amount of time to respond to the authority's request.

\section{Design and Procedure}

The subject was brought into the chemistry classroom and was seated facing the rigged cabinet. An experimenter placed a mock personality
\end{abstract}

Requests for reprints should be sent to Janis Sackhoff, P.O. Box 293, Beloit, KS 67420 .

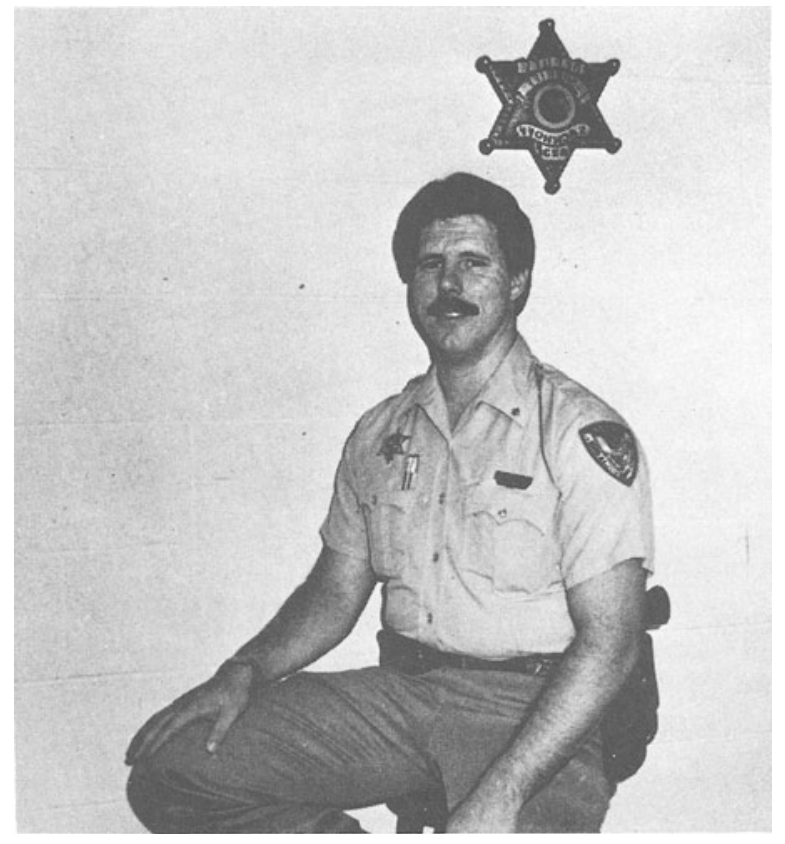

Figure 1. Richard Sackhoff served as the authority figure. Photograph printed with permission of Richard Sackhoff.

inventory before the subject, told the subject to complete it, and left the room, telling the subject that she would return in a few minutes. Each subject was given $1 \mathrm{~min}$ to begin the inventory before the authority figure entered the room. He made the same request to each subject: "I am late for a meeting with your Dean. I want you to get in that cabinet [pointing to it] and take the box inside to the President's office immediately!' The experimenters viewed the subject on a television monitor and waited for his/her response. An obedient response was defined as the subject's opening the cabinet door 1 in. or more. After $3 \mathrm{~min}$, if the subject had not obeyed, the experimenter returned to the room and ended the experiment by debriefing the subject on all aspects of the experiment. The subject was asked to not discuss the experiment with anyone until it had been completed, and was invited to attend a meeting concerning the results of the experiment. This procedure was repeated for each subject. 


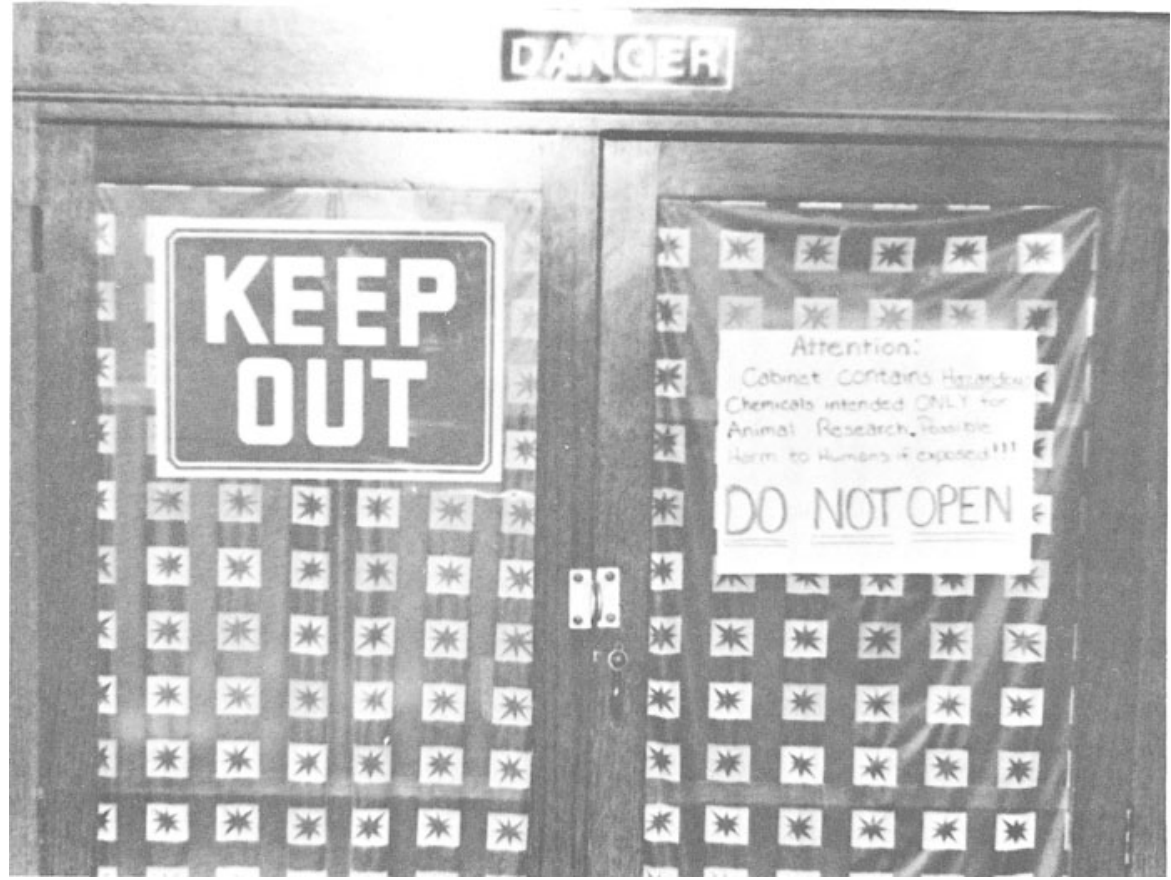

Figure 2. The rigged cabinet.

\section{RESULTS}

A chi-square was used to compare the numbers of subjects who obeyed and disobeyed $\left[\chi^{2}(1, N=17)=4.76\right.$, $p<.05$ ]. Four obeyed and 13 disobeyed. Each subject was questioned after his/her session about the purpose of the experiment. All stated that prior to debriefing they felt the purpose was only to complete the personality inventory.

\section{DISCUSSION}

The results of this study are contrary to those obtained by Milgram (1963). It appears that obedience to authority has differential effects: subjects are unlikely to obey if the authority's request places the subject him/herself in potential danger, but they tend to obey if the victim is a third party and the subject is safe.

Additional research should be conducted to determine whether the results of the present study would vary according to differences in the authoritative personalities, or according to different types of danger presented to the subjects. Moreover, a larger sample in various other situations should be used.

\section{REFERENCE}

Milgram, S. (1963). Behavioral study of obedience. Journal of $A b$ normal Psychology, 67, 371-378.

(Manuscript received for publication November 23, 1987.) 